Bundesgesundheitsbl 2019 $\cdot 62: 534$

https://doi.org/10.1007/s00103-019-02933-x

Online publiziert: 26. März 2019

(c) Springer-Verlag GmbH Deutschland, ein Teil von Springer Nature 2019

Thorsten Rieck ${ }^{1,2} \cdot$ Dorothea Matysiak-Klose' $^{1}$ Wiebke Hellenbrand' Judith Koch · Marcel Feig' · Anette Siedler' · Ole Wichmann'

'Abteilung für Infektionsepidemiologie, Robert Koch-Institut, Berlin, Deutschland

${ }^{2}$ Charité Universitätsmedizin Berlin, Berlin, Deutschland

\title{
Erratum zu: Umsetzung der Masern- und Pertussisimpfempfehlungen für Erwachsene
}

\section{Erratum zu:}

Bundesgesundheitsbl 2019

https://doi.org/10.1007/s00103-019-

02902-4

In der Originalfassung des Artikels wurde leider ein inkorrekter Wert für die 10Jahres-Impfquote für Diptherie genannt. Korrekt lautet der entsprechende Satz wie folgt:

Während die 10-Jahres-Impfquote für Diphtherie $(51,1 \%)$ in der Größenordnung von anderen Erhebungen lag, lag die 10-Jahres-Impfquote für Tetanus rund 20 Prozentpunkte darunter $[15,23]$.

Der Originalartikel wurde korrigiert.

\section{Korrespondenzadresse}

Dipl.-Biol. Thorsten Rieck, MSclH

Abteilung für Infektionsepidemiologie,

Robert Koch-Institut

Berlin, Deutschland

RieckT@rki.de
Die Online-Version des Originalartikels ist unter https://doi.org/10.1007/s00103-019-02902-4 zufinden. 